\title{
ASEAN's Regional Integration Challenge: The ASEAN Process
}

\author{
BENNY TEH CHENG GUAN
}

\begin{abstract}
ASEAN's development, though gradual and slow, has consistently demonstrated an uphill shift from a focus on regional peace and stability to closer economic integration. Amid economic difficulties, ASEAN took on the task of setting goals for the region as clearly laid out by Vision 2020. The vision for the future goes beyond the two-page Bangkok Declaration set in 1967. The ultimate goal is to achieve an integrated ASEAN community with a common regional identity. Considering the downturns and problems that are affecting the organization, scholars have argued that successful integration is highly unlikely for ASEAN. The route is laden with obstacles that urgently need to be cleared. Based on this understanding, the paper first reviews the analysis of the determinants of the success and failure of regional integration. It then attempts to show that there lies a deeper root cause of concern, one that has been fundamentally imbedded and has come to dictate the working traditions of ASEAN. Proper reconfiguration and supplementation of the ASEAN process is a key necessity to reviving ASEAN's dynamism and competitiveness and as such should not be sidelined any longer.*
\end{abstract}

\section{Introduction}

Regional institutions are constantly challenged by the changing times that are an integral facet of an anarchic international system. In times of change, adaptation and adjustment are important to maintain their significance and reliability. Some organizations weathered the test of time while some faltered and withered away into the background of global politics. Throughout history, there have been numerous regional groupings with differing goals but mostly centred around political and economic objectives. Of the many regional integration plans or initiatives that have surfaced over time in various parts of the world, only a handful have materialized into well-established institutions, the two most successful being the European Union (EU) and the North American Free Trade Agreement (NAFTA). In Asia, the Association of Southeast Asian Nations (ASEAN) is a good example of a regional integration scheme. 
ASEAN's creation was initially for security. It was neither formed to integrate member economies nor to build a supranational institution. While it is an undisputed fact that ASEAN and the EU have very different orientations, both were originally created for the preservation of peace and security in their respective regions. The Europeans realized that a new European institution was needed to constrain Germany. Similarly, ASEAN was formed to constrain Indonesia. As Konfrontasi (confrontation) was a clear indication of Indonesia's powerful military might that stands to destabilize the region, the establishment of ASEAN was a direct response to the intra-regional stimulus of Sukarno's Konfrontasi. Drawing a somewhat analogous line to the downfall of Germany's Hitler, ASEAN became viable and visible only after a change in Indonesia's leadership had occurred. While the European community moved closer towards economic integration through the Treaty of Rome (1957), ASEAN has, to some degree, strengthened its foundation in security cooperation; first, with the 1971 declaration of a Zone of Peace, Freedom and Neutrality (ZOPFAN) and second, during the 1976 Bali Conference that produced the Treaty of Amity and Cooperation in Southeast Asia (TAC). Economic cooperation was minimal. ASEAN members' economic attainments were the makings of individual policies and their dealings with the broader international economy and had very little to do with ASEAN as an organization (Charterjee 1990). This explains why there have been rather limited complimentary economic policies due to low intra-ASEAN trade.

While ASEAN was focusing more on security issues throughout the Cold War period, movements toward economic integration became more visible in the post-Cold War era. Indeed, 1992 was seen as the year that 'launched' the economic integration of ASEAN. A series of economic-related proposals and adoptions have been made since then. Those include the Common Effective Preferential Tariff (CEPT) scheme for the ASEAN Free Trade Area (AFTA) in 1992, the Framework Agreement on Services and agreement on Intellectual Property in 1995, the Protocol on Dispute Settlement Mechanism in 1996, ASEAN Investment Area agreement and the Framework Agreement on the Facilitation of Goods in Transit in 1998, the e-ASEAN framework in 2000 and to a certain extent the ASEAN Tourism agreement in 2002. Many of these are legally binding documents that probably show ASEAN's growing realization for the need to have legal binding foundations if integration is to succeed. According to Takeuchi, there are four factors contributing to ASEAN's increased interest in regional economic integration: the 
need to balance China's, as well as the former Soviet Union and Eastern Europe's, competition for foreign investment; the fear of future exports being affected by the formation of NAFTA and the closely integrated $\mathrm{EU}$; the perceived convergence of regional economic relationships among member states; and the necessity 'to keep regional liberalization one step ahead of the WTO and APEC at all times' (Takeuchi 1999: 123-24). Apart from the four, the 1997 Asian financial crisis is surely a contributing factor to faster and closer economic cooperation in order to build regional resilience against external volatilities. The 1977 ASEAN currency swap arrangement, for example, was resuscitated and extended under the 2000 Chiang Mai Initiative (CMI). Furthermore, it was during the onslaught of the Asian meltdown that ASEAN members reaffirmed their commitment for regional solidarity, producing the ASEAN Vision 2020 statement. This is a step higher than the 1967 Bangkok Declaration, with 'closer cohesion and economic integration' clearly spelled out, as compared to the thirty year old ambiguous two-page declaration. As a result, ASEAN as a regional organization has gradually shifted from merely a loose security arrangement to one that is working towards being a fully integrated community. Under this notion, it is possible to gauge if an ASEAN community bound by a common regional identity as stated in Vision 2020 could be achieved or not, based on an analytical framework of the determinants of the success and failure of regional integration. ${ }^{1}$

In reviewing the analytical framework, this paper attempts to show that there lies a deeper root cause of concern, one that points to the working traditions and diplomatic culture of ASEAN. Thus the objectives of this paper are two-fold. Firstly, it will be argued that the prospect of attaining the 'stated integration goal' as envisioned by Vision 2020 is strongly related to the concept of the ASEAN way or the ASEAN process. By emphasizing consultation and consensus, this concept serves as the bedrock of how ASEAN functions as an organization, internally and externally as well as politically, economically and socially.

By tying it to the first, my second argument is that this process, being the most important centripetal force, is not capable of leading ASEAN towards a successful regionally integrated institution in this global new age even though ASEAN has achieved some past successes from it. Hence, for integration to succeed the conceptualization of the norms of procedure need to be rethought and some degree of sovereignty has to be negotiated. This paper is organized into two sections. The first part examines and identifies a common denominator based on the defined analytical framework of ASEAN as a regional integration scheme and 
the second part looks into key areas that require reformulation and change by ASEAN to pursue its integration quest. Here, it should be made clear that the reasoning of the success and failure of regional integration should not be confused with the reasoning of the attempts at regional integration.

\section{Defining the ASEAN Diplomacy}

The 'ASEAN way' or the 'ASEAN process' is understood to have been posited under the theory of constructivism, which was seen as an attempt to respond to the realist approach regarding factors determining state interactions in Southeast Asia. Constructivist scholars conceive that through a shared collective identity, ASEAN has built a set of norms defining states' behaviour that each member state is required to adhere to. ${ }^{2}$ In a broader perspective, these ASEAN values or norms are 'the hybrid offspring of an Asian value system' and the development of ASEAN 'has been guided in part by the underlying beliefs and principles of Asian values' (Noor 1999: 166). Unfortunately, they do not reflect the value system of ASEAN peoples as a whole. Arguing that 'the development of a non-elite and more popular sense of common ASEAN identity' may be hindered, Noor stated that 'the ascendancy of an elite discourse based upon a common elite political culture and value framework [of the traditional ruling elite] may well retard the progress and development of an ASEAN organization that is dedicated to the interests of ASEAN citizens themselves' (Noor 1999: 166). Indeed, the ASEAN way, if any, provides a sense of regional identity only at the intergovernmental level. A people's ASEAN has yet to be realized. As echoed by a former Thai Foreign Minister, the future of ASEAN should become 'an ASEAN of the people, [and] not just an ASEAN of government leaders' (Pitsuwan 2001: 8).

As the ASEAN way is an evolving interactive process, it is not easily defined. Haacke noted that there are at least three distinct conceptualizations of the ASEAN way. First, it is 'an intramural approach to dispute management and confidence building'. Second, it is a decision-making method associated with the principles of musjawarah (consultation) and mufakat (consensus) that is originally a native political process built on ancient Javanese customs which basically express ways of resolving political and personal differences through lengthy consideration concluding in unanimous decision. The third refers to Acharya's conceptualization that is a 'process of identity building which relies upon conventional modern principles of interstate relations as well as tradi- 
tional and culture-specific modes of socialization and decision-making' (Haacke 2003: 58-59; Acharya 2001: 28). ${ }^{3}$ For the purpose of this article, the ASEAN way denotes a broad definition that covers both the basic international norms and the socio-cultural norms steering interaction among the ten Southeast Asian members. Key features would mainly include respect for sovereignty, non-interference, non-use of force, quiet diplomacy (which may include informality and saving face), non-involvement of the organization in bilateral disputes and mutual respect (for the sensitivity of others), frequent consultations, consensus-building, accommodation, discretion and conciliation.

\section{The Requirements for Successful Regional Integration}

What exactly constitutes a successful regional institution? As mentioned earlier, why do only a few regional organizations succeed among the many? Walter Mattli points out that the success of a voluntary regional integration plan depends critically on the demand and supply condition. An area with a significant cross-border exchange of trade will lead to strong market pressure for integration, which Mattli labels as a demand condition. Conversely, the integration process will come to a halt if the potentiality for gain is very low due to certain factors like the lack of complementarity among regional economies or the absence of vital economies of scale. Success, according to him, is defined as the realization of 'stated integration goals'.

As for the supply condition, each plan or scheme must have the presence of a munificent leader/country that will act as a central figure in the coordination of rules, regulations, and policies and assist in easing tensions that may 'arise from the inequitable distribution of gains from integration' (Mattli 1999: 42). Those two conditions above are considered by Mattli to be of primary importance. A third less-crucial condition would be the creation of 'commitment institutions' as third party enforcers in helping to catalyze the integration process by improving 'compliance with the rules of cooperation' and preventing reneging (Mattli 1999: 42-43).

Another key point put forward is the notion that political leaders who face economic difficulties at home will promote regional integration if they are convinced that their political survival depends on it. Two current integration schemes that satisfy Mattli's primary conditions are the EU and NAFTA, led by Germany and the United States respectively. In the case of the EU, the European Commission and the European Court of Justice are seen as examples of 'commitment institutions' fostering integration. 
Mattli's explanatory framework is not without limitations. Douglas Webber briefly provided six objections or reservations, questioning Mattli's conditions of successful integration. He notes that: firstly, policies to integrate markets in creating a free trade area or common market should not be the only focus as there can also be emphasis on the 'integration or coordination of other kinds of policies' in some regional integration schemes, although it stopped short of explaining what are those kinds of policies and how they are related to the success and failure of integration; secondly, there should be an explanation of interregional variations of 'stated integration goals' such as why the EU's integration agenda seems to be more thorough and far-reaching than NAFTA's; thirdly, 'a coalition of leading states' apart from a hegemonic state do stand a chance to provide the obligatory leadership for successful integration citing the close bilateral relationship of France and Germany as a more realistic interpretation of EU's success; fourthly, 'commitment institutions' should not be seen as only a pre-condition but they can also emerge as the consequences of successful integration; fifthly, economic difficulties as a condition may not necessarily encourage regional cooperation and even if it does, it may help to explain the attempt at, rather than the success/failure of regional integration; and lastly, the stipulation of leadership role is not only determined by hard variables (economic size, population, and military strength) but may also be dependent on soft variables (foreign policy strategies, history, and collective memories) (Webber 2001: 344-45). While accepting Mattli's first two 'strong' conditions and rejecting the others, Webber put forth another two of his own - the 'degree of economic and political homogeneity' - and the role of the United States (US) in influencing regional integration projects (Webber 2001: 347).

\section{Identifying the Impeding Factor}

Based on the conditions as spelled out in the previous section, both Mattli and Webber took to the task of analyzing ASEAN as a regional integration scheme/project. The results of their individual analysis were daunting. As shown in Table 1, Mattli provided three reasons and Webber four as to why ASEAN would not succeed in its 'stated integration goals'.

Both Mattli and Webber agreed on the first two reasons (see Table 1). The first reason of 'low and non-complementary intra-regional trade' cannot be simply understood in economic terms but should be put in a historical context. ASEAN as an organization was borne out of regional 
TABLE 1: Reasons Why ASEAN is not a Successful Regional Institution

\begin{tabular}{|l|l|l|}
\hline Pre-Conditions & \multicolumn{1}{|c|}{ Mattli } & \multicolumn{1}{c|}{ Webber } \\
\hline Strong market pressure & Low and non-complementary intra-regional trade \\
\hline Undisputed leadership & Lack an undisputed leader \\
\hline 'Commitment institutions' & $\begin{array}{l}\text { No central monitor- } \\
\text { ing or third-party } \\
\text { enforcement }\end{array}$ & \\
\hline $\begin{array}{l}\text { Economic \& political } \\
\text { homogeneity }\end{array}$ & - & $\begin{array}{l}\text { High level of disparities } \\
\text { in economic development } \\
\text { and openness. }\end{array}$ \\
\hline The US factor & - & 'Benign indifference' \\
\hline
\end{tabular}

Sources: Adapted from Mattli (1999: 169-71) and Webber (2001: 351-53).

conflict whereby the founding leaders had no agenda of integrating member economies even though that notion was not alien to them as they were much aware of what was transpiring in Western Europe. Moreover, Southeast Asian countries' economic successes, especially among the ASEAN-five, prior to the economic crisis, were achieved through individual efforts under the directives of each nation's own national economic policies. Most of them share the same markets and compete in the same industrial sectors. As history has shown, the bulk of early cooperation among member-states was in the areas of security, first with the communist insurgencies, followed by superpower rivalries and the invasion in neighbouring Indochina (Vietnam-Cambodia issue). Serious economic cooperation only took off after the Cold War ended, mostly attributed to the trepidation of NAFTA's and the EU's integration plans. Also, this is related to the unsuccessful attempt of an East Asian Economic Group/Caucus (EAEG/EAEC) proposed by Malaysian Prime Minister, Dr Mahathir Mohamad, in 1990. Had the EAEG proposal gone through, AFTA might not have come about or may have been realized in a different form. ${ }^{4}$ While economic integration has been somewhat expedited since then, more so after the economic crisis, intra trade has generally remained low. In 1993, trade among the ten Southeast Asian countries stood at around 22 percent of total exports and in 2002 it was only at 24 percent (WTO Trade Statistics 2003).

There are two possible reasons to this. First, ASEAN is incapable of drawing up any kind of treaty like the 1957 Treaty of Rome establishing the European Economic Community. A treaty with clear rules and procedures would have arguably bound and ensured commitment from 
member-states. This inability is tied to a political culture, which holds sovereignty and non-interference sacred, as enshrined in TAC. As the Association becomes more firmly sheathed within its norms, it faces a tougher time to create institutional structures that are essential in increasing intra-trade and deepening economic integration. The ASEAN way helped to achieve political stability in the region and so provided a conducive environment for foreign investment but it failed to enable member-states to capitalize on such opportunities collectively.

Second, the generally authoritarian nature of Southeast Asian governments kept the region 'divided' and limited economic integration. From a realist perspective, the dominant goal of authoritarian leaders is to remain in power, thus the survival of the individual leader surpasses the interest of the state. ${ }^{5}$ Closer economic integration or the establishment of a treaty would lead to a trans-national organization and the subsequent loss of power in directing their respective national economies. Thus ASEAN norms (sovereignty, non-interference and consensual decision-making process) augment authoritarianism and preserve the divisions of nation-state identities. Those norms also provide an escape route if member states fail to agree on a common policy. As countries pursue their own economic agendas, they face difficulties in collective coordination of their economies, eventually leading to competition rather than complementarity. The formation of AFTA and the signing of various economic agreements reflected the awareness of external market forces like globalization rather than strong internal needs for market integration. Implementations of those agreements continue to remain a problem. ${ }^{6}$

The second reason was that ASEAN does not have an undisputed leader or a coalition of leaders to guide the organization. Indonesia, with the largest population and one of the strongest military, is often looked upon as the organization's leader. Indeed, the stationing of the Association's secretariat in Jakarta shows the recognition of Indonesia's importance in the region. Even the concept of musjawarah and mufakat originated from the traditional Indonesian village system, which became the standard norms of conduct for ASEAN. The fall of Suharto and the political and economical uncertainties that befell Indonesia thereafter are partly blamed for the disruption of ASEAN's goal in achieving an integrated community. Indonesia was important to ASEAN at the time of inception because of her size and military strength. By getting Indonesia to commit to ASEAN, it was hoped that any future mischief could be deterred. 
But within ASEAN, Indonesia could hardly assert its leadership role as others were sceptical of her intentions or downplayed her position. Referring back to history, it's possible to provide a few examples. When Suharto first tried to lead the other founding members towards nonalignment as a response to foreign power rivalries, none followed. Malaysia and Thailand were subdued but the Philippines had no intention of giving up their strong bilateral defence ties with the US and the Singaporeans wanted to continue relying on British protection. Obviously, they saw external actors as vital in preventing Indonesia from dominating the region (Leifer 1989: 5-6). Another case of interest was the Vietnam-Cambodia issue - the invasion and occupation of Cambodia by Vietnam from 1978-90. Geographical proximity and external power interference were threatening ASEAN's security and thus saw the need to pull their strengths together. On the surface, it showed unity and managed to gain recognition from the international community. However, things were murkier below the surface. Indonesia, which received the backing of ASEAN as interlocutor in that issue, was later undermined by Thailand's own independent approach in solving the matter. ${ }^{7}$ Such tacit manoeuvring clearly showed the limitation of Indonesia's reputation within the organization. A third example is best displayed by the proposal of EAEG by Malaysia. The unilateral approach taken not only irked the Indonesian camp but also put Indonesia's headship into question. Furthermore, while Indonesia may be strong militarily, it is relatively weak in economic terms, even more so now as it grapples with democratic transition. This has greatly prevented it from becoming the 'regional paymaster' in easing any distributional problems unlike what Germany was capable of doing for the EU.

The limitation of Indonesia or any other members to hold the role of undisputed leader is manifested in the ASEAN process. The norms of procedure deny Indonesia any outright leadership role. ${ }^{8}$ Under musjawarah, a leader is not allowed to act capriciously or forcefully and any suggestions given should take into consideration the views and feelings of fellow members. Mufakat will be achieved when all members agreed to those suggestions. The outcome is not only slow but reflecting the lowest common denominator. In this sense, the alleged hard and soft variables that determines an undisputed leadership role as submitted by Webber is less applicable in the case of ASEAN due to the presence of those unique norms of diplomacy that sets the organization apart from other regional entities. 
As for the third reason based on Mattli's 'commitment institutions', it is obvious that ASEAN lacks third-party enforcement machineries and this becomes very clear when compared to the EU. However, this reasoning irrespective of whether it is a pre-condition or a consequence of successful integration as Webber would argue has to be understood from the political culture that ASEAN operates in. Member-states have been frequently accused of not being willing to shift any decision-making authority to higher supranational bodies. Any bilateral disputes that arise between members are mostly handled through quiet diplomacy where the organization is not involved. Disputes that cannot be settled are often put off to a later period. A case in point is the Philippines's claim over Sabah in the 1960s. It was suppressed after Marcos came into power and gave verbal assurance, but since no official treaty was signed, future dispute still remains highly possible. If trouble becomes unbearable, it is then referred to an outer international body and not ASEAN itself. This is true of the case between Malaysia and Indonesia over the jurisdiction of Sipadan and Ligitan islands. The same holds for the recent dispute between Malaysia and Singapore over the strategic island of Batu Puteh (or Pedra Branca).

The inability to draft its own effective 'commitment institutions' and the reluctant reliance on international dispute settlement mechanisms could be seen as due to the practice of the ASEAN way that greatly puts constraint on the viability and implementation of such institutions. It clearly brings into question the norms of sovereignty and non-interference that are at the very centrepiece of ASEAN's foreign policy. This is the underlying factor to Mattli's definition of 'commitment institutions'. Without prior resolve of those norms, commitment and compliance would not be possible since it would undermine the powers of the individual leaders and the sovereignty statuses of member countries, all of which with the exception of Thailand experienced the harsh realities of colonialism and thus prize those values more highly than their Western counterparts.

If the goal is only to reduce tensions and war in the region, then the ASEAN process can be likened to a unique kind of commitment 'institution', at least not within Mattli's classification, that has created 'stable expectations' and acts as a monitoring mechanism of mutually acceptable behaviour in setting the course for any cooperative undertaking. However, ASEAN's goals go beyond that narrow definition and norms alone obviously remain inferior to legal rules. As Nischalke (2000: 89-112) points out in his research, there were instances when those fundamental principles have been breached. 
In 1999, there were calls for more concrete measures to be taken in solving problems that had beset the organization. Saying that the ASEAN way can no longer be maintained, former Indonesian foreign affairs advisor Dewi Fortuna Anwar called for a crisis-management centre similar to the Organization for Security and Cooperation in Europe (OSCE) to be set up (International Herald Tribune, 22 April 1999). What transpired was the creation of the ASEAN Troika (2000) and the ASEAN High Council (2001). Some may tend to argue that they do represent a form of 'commitment institutions' with the purpose of providing a channel to manage and resolve disputes among members. Briefly, the ASEAN Troika is meant to deal with sudden flare up of disputes while the High Council is intended to deal with long-term disputes. They are claimed to be seen as a small step away from the traditional diplomatic culture of ASEAN. Indeed, it does reflect a shift from the traditional norm of non-involvement of the Association in any bilateral disputes.

However, their effectiveness is put into question. Several reasons could be identified. First, the ASEAN Troika has failed to materialize as a permanent institution at the ministerial level. Instead it ended up as an ad hoc body. Thailand's Prime Minister Chuan Leekpai's proposal to institutionalize the Troika concept was seen by others as a 'clever effort to revitalize Surin Pitsuwan's proposal of flexible engagement in different garb' (Haacke 2003: 72). Second, it is not allowed to make any decisions on its own but only to offer recommendations in assisting the ASEAN Foreign Ministers. Third, the Troika is subjected to the guidelines of the norms of procedure, specifically non-interference and consensus. All these point to the fact that the ASEAN way has not been diminished but rather enhanced.

Not only it is important to prevent intervention from outside powers but also individual leaders are still reluctant to involve other regional members in their respective domestic affairs. Comparably, ASEAN's Troika is unmatched to the OSCE even though principles of sovereign equality, non-intervention, peaceful settlement of disputes, territorial integrity, etc are also enshrined in the OSCE. On the rules of the procedure of the ASEAN High Council, Haacke clearly noted that 'some of the rules of procedure reinforce rather than undermine existing norms of the ASEAN way' (Haacke 2003: 79). In contrast to the OSCE that allows any member nation to call for a dispute to be brought up before a commission, the High Council could be invoked only by the state involved in the dispute, hence very much inline to the norms of non-interference and sovereignty. Whether they are just political gestures or have the 
might to solve ASEAN's woes are yet unknown. But even as the ASEANsix may try to reinvent the organization in a more structured fashion, the ASEAN-four (Cambodia, Vietnam, Laos and Myanmar - CVLM countries) will continue to resist and clam tight the diplomatic culture that they have come to identify with.

On Webber's third point, he argued that ASEAN is incapable of achieving closer or successful integration primarily because there are high disparities in the economic level of member-states that would obstruct any efforts toward collective actions. In other words, the political and economic climate in Southeast Asia is too heterogeneous to achieve a 'sense of community' or a common identity, which he believes to be the prerequisite for a successful regional organization. Here, the EU is once again evoked as a comparison. But while disparities may obstruct the integration process, it is not necessarily a strong argument.

Claiming a degree of homogeneity among state actors in a region as a variable for comparison does, to some extent, deny the fact that until today there has not been any regional organization visible in Northeast Asia where the countries of China, Japan and Korea share more similarities in many respects than the countries in Southeast Asia. Japan and Korea exhibit a wide range of economic and cultural resemblance. Economic cooperation through trade between the two countries has generated extensive business networks. Japanese trade and investment, not to mention developmental assistance, with China and China's shift to a market economy should have brought about some form of organizational structure for cooperation in the region. Or, even the fact that the Gulf Cooperation Council (GCC) established in 1981 among countries with similar cultural traits has remained weak and insignificant for two decades. Discrepancies in political and economic systems or lingering historical animosities are as or could even be more essential hurdles to regional integration in comparison to religious or cultural qualities. The ability of ASEAN to bring the three Northeast Asian countries into economic cooperation through the ASEAN+3 Process stand to further weaken Webber's point above.

A more fundamental factor in the obstruction of collective action and crisis management in ASEAN should be directed at the norms of procedure that have developed over a long period of time. The seeing of themselves as feeble states and hence the need to uphold power and maintain sovereign rights not as a region but as individual states has exacerbated foreign policy divergence and, coupled with the overarching of protectionism especially among newer members, do not bode well 
in breaking down the walls of political divisions. The ASEAN way has been 'highly successful at altering the interactions' of members but it is neither capable nor designed to 'alter their definitions of their national interests' (Narine 1997: 965). This limitation is a key factor in hindering the cooperative process towards shared common political values and goals of the organization.

The fourth and final reason was about how the United States perceives regional integration plans in regions that fall under its sphere of influence. Here, Webber argues that without the Johnson Administration's approval and the critical role it played, ASEAN would not have come to life. ASEAN received US support due to its anti-communist raison d'être, which was 'entirely congruent' with the US's objectives of that time, while its current attitude towards the Association is one of 'benign indifference' (Webber 2001: 351-53). The view that ASEAN succeeded in its creation because of US approval is rather misleading. ASEAN's initial focus on communism may have run parallel to President Johnson's Asian policy but its formation was much less of a US influence.

As Yamakage clearly points out that ASEAN was never a part of any US anti-communist strategy. Indonesia, which proposed the name of ASEAN and wished to incorporate the principle of nonalignment into the organization, was never aware of any attempts to use ASEAN as an anti-communist satellite. Policies taken by ASEAN governments were actually disassociated from US policy. He notes that on the contrary, fear of US withdrawal from the region and over dependence on the US were factors that led Southeast Asian countries to form ASEAN (Yamakage 1997). ${ }^{9}$

Nonetheless, the US factor can be best understood when the failed EAEG is taken as an example. The reason for the failure of the EAEG plan was principally the mistaken exclusion of US from the equation. Other factors notwithstanding, had the EAEG been defined along the lines of open regionalism and assured US interests, an East Asian organization could have emerged. But, as Webber admits, it is a factor concerning the success or failure of attempts at regional integration for states that are susceptible to American pressure. US presence may help accelerate the integration process by providing security and maintaining stability in a region or decelerate it by influencing the policies of regional states. European integration plans in the early period were strongly supported by the US, which provided the security role of containing Germany, thus giving France adequate confidence to construct a bilateral relationship with Germany. 
US presence in Southeast Asia has also played an integral part in stabilizing the region. However, it does not qualify as a pre-condition for successful regional integration. The US factor failed to be sustainable as is clearly proved when ASEAN asserted its independence and voted to admit Myanmar in 1997 in plain defiance against the US stance. Although admitting Myanmar remains a controversial issue, ASEAN went a step closer to achieving its long-term goal of uniting all of Southeast Asia. ${ }^{10}$ Therefore, even if the US shows 'benign indifference' to ASEAN, there should be no grounds for the organization to derail from its course. What is obstructing ASEAN's path to closer integration is not the US but rather the lack of a shared vision and political unity among the members. The ASEAN process that defines how ASEAN operates clearly limits the organization's ability to move towards stronger and deeper integration. It is more of an internal condition than an external factor.

\section{Reformulating the ASEAN Way}

The above analysis mostly showed an existence of a common denominator - the ASEAN way. The reasons promulgated by Mattli and Webber of ASEAN as a 'failed' regional integration scheme is actually tied to a deeper root cause that specifically points to the nature of the organization's diplomatic culture. While recognizing the ASEAN process as embedded in the system, the paper calls for necessary reconfiguration and supplementation in line with the changing regional and international landscape.

There has been some reluctant progress to date. In 1998, an attempt was made in the effort to readjust the ASEAN way through a policy proposal of 'flexible engagement'. It was a realization by some quarters that there is a need to shift towards a more transparent and open discussion. This realization came after the Association was highly criticized and blamed for its failure to unite and manage the Asian financial crisis collectively. However, there was resistance against the proposal. Then Malaysian Foreign Minister, Abdullah Ahmad Badawi, made his stance clear when he wrote 'I believe in consultation, definitely not intervention - flexible or otherwise' (Asiaweek, 25 December 1998). The proposal was finally rejected largely because the concept itself was poorly spelled out and there were fear among members that it would undermine regime security (Haacke 1999: 592-98). Instead, member countries settled for a less impressive formula of 'enhanced interaction'.

The new adopted terminology allows member states to convene and discuss problems when a domestic concern of one country produces 
vibrating effects on other countries and when transnational problems like drug trafficking, smuggling, and piracy require cooperative efforts. In practice, it has not wavered much from the general agreed code of conduct, as even Thailand, which came up with the proposal, has kept much of its interaction rather compatible with ASEAN's traditional diplomacy. Agreements like the Transboundary Haze Pollution, the ASEAN Troika and the High Council, signed after 1998, are meant to provide a more institutionalized approach to problem solving. It may show a general move towards loosening the grip primarily on the norm of non-interference. But these agreements do demonstrate a flaw. As explained in the previous section, only the country involved in a dispute or a problem can raise the issue for discussion. The question then becomes what happens when a member country decides not to do so with a domestic problem that has turned into a regional one. Power continues to be vested at the national level and since there are no means of forcing compliance, there will be obstacles in implementing those agreements. Quiet diplomacy still reigns, more so in the post-Asian crisis as the Southeast Asian countries busily continue to engage in nation-building.

While the ASEAN way has brought relative peace to the region, it clearly demonstrates insufficiency in providing a strong platform for regional integration. The paradox is that a total abandonment would risk threatening ASEAN's own survival but full preservation will only cause the organization to lose out (Kuroyanagi 2003: 170-71). Since there is a strong desire to go beyond the current level of cooperation as further indicated in the 2003 Bali Concord II Declaration for Economic, Security and Socio-cultural communities, the ASEAN way ought to be rethought. The supplementation of 'commitment institutions' and the reconfiguration of at least three key norms - sovereignty, non-interference and consensus - are indispensable in achieving the objectives of ASEAN.

\section{'Commitment Institutions'}

It is difficult to envision a strong integrated ASEAN without having effective forms of commitment institutions in place. Democratization and further economic integration may encourage member countries to see beyond their narrow individual interests and open the door for mutual acceptance of higher institutional structures. 'Commitment institutions' would serve as pivotal pillars that would help to constrain the members from reneging on the rules of cooperation. This would lead to the enhancement of transparency in the workings of ASEAN and reduce 
the need for quiet diplomacy. It will also ensure that the countries stay committed to the many initiatives and projects like AFTA, AIA and other new ones being introduced.

ASEAN has been introducing various initiatives to keep up with global developments. As those initiatives become more sophisticated, institutionalization beyond the state would be inevitable or else there will be further disparities and unevenness if left to the devices of individual states. Without doubt, ASEAN has to reinvent itself. At the current stage, the ASEAN process would make any proposition of 'commitment institutions' improbable. As yet, there is still a lack of preparedness to pool sovereignty in a way that is beneficial for the entire region and its wider population. A 'super structure of politics' may be what the organization needs to integrate the differing political cultures of member states (Pitsuwan 2001: 10). The more the Association is able to change its current diverse governance structure into a more homogenized form through the cultivation of a common set of political values, the better it will succeed in its integration plans. Thus, ASEAN has to assign itself the task of converting its members into a standardized political set-up.

To date, the Association has identified the need to strengthen its Secretariat by enhancing its role and sharpening its priorities. However, this should also duly include the transfer of more authority for it to function as a respected central and legal body governing the ten member countries. While political divisions continue to be a dilemma for ASEAN, it has come up with some ambitious plans on the economic front. Under the Roadmap for Integration of ASEAN (RIA), there are three main pillars: firstly, to narrow the economic development gap of the organization's older and newer members through a six-year Initiative for ASEAN Integration (IAI) work plan (July 2002-June 2008); secondly, to deepen economic cooperation in areas like energy (ASEAN Power Grid), transport (ASEAN Highway Network) and sub-regional growth areas; and thirdly, to improve economic cooperation through market integration initiatives such as AFTA and ASEAN Investment Area. These projects require proper management and extensive coordination as well as effective dispute mechanisms to ensure their success. With the supplementation of 'commitment institutions', not only will the projects be better managed but it will also certainly raise ASEAN's competitiveness amid other regional groupings and avoid being marginalized. The realization of such institutions will, however, depend on two key norms - sovereignty and non-interference. 


\section{Sovereignty and Non-interference}

The cardinal principle, sovereignty, and its corollary principle, non-interference or non-intervention, are perceived as the most problematic concepts which obstruct successful integration. While both principles date back as far as the Westphalia agreement of 1648 and have been serving as the basic rule of interstate relationship in the world, ASEAN took to them as its sacred tenet. These principles allowed ASEAN to be formed as a regional organization in a region beset with mutual suspicion, distrust and political rivalry. Intermittent intervention in internal affairs notwithstanding, only through these principles could ASEAN assure regime security for its members, that in return assures the Association's survival.

Sovereignty-bound, ASEAN took the role of controlling conflict between member parties. Together with other norms that came to define the ASEAN way, community building was gradually made possible. While ASEAN was not a fully-fledged security community, it demonstrated some of the characteristics of no armed interstate conflict and military build-up (see Acharya 1995: 175-200; Narine 2002: 71-74). The beginning of the 1990s saw a different kind of challenge, an economic one that would seriously flout the principle of sovereignty. The current waves of fluid movements in the global arena with the advent of globalization, domestic issues increasingly manifest themselves into diplomatic problems and the emerging civil societies of Southeast Asia are all taking great toll of the traditional principles of absolute sovereignty and non-interference.

The principle of non-interference in domestic affairs is a significant barrier that impedes the capability to achieve far greater integration. Can there be a high level of integration by strictly adhering to this principle? The 1997 crisis has proved how disastrous it can be for the region. It has shown that as the countries in the region become more and more interdependent, the old argument of non-interference become less and less attractive. Sooner or later it has to be discarded, for every Southeast Asian country should be its brother's keeper. The adoption of enhanced interaction, while minimal, is a good start. At least it shows leaders' willingness to engage in discussion. But obviously it is inadequate. If ASEAN wants to solve its own problems and avoid being divided into the haves and have-nots, the members will have to engage each other in a more mature and constructive environment. This is where the ASEAN-six can teach by example. The alternative would be to wait for all the member states to become fully democratic (Yamakage 2001: 139-40). ${ }^{11}$ But even 
then, being democratic alone does not suffice. It has to be coupled with economic prosperity to create confidence. Unfortunately, what the Association does not have is time.

Most member countries are fearful of having a strong functional ASEAN for fear of incurring a diminished national policymaking autonomy. However, the issue is not entirely about ceding some colossal principle of sovereignty. It is more specifically about engaging in 'sovereignty bargains' - the acceptance of certain limitation in exchange for other benefits (Litfin 1997). With sovereignty comprising three elements of autonomy (or independence in policymaking and action), control (the ability to produce an effect), and legitimacy (the recognized right to make rules), a state may bargain for more control over autonomy or have its legitimacy undercut by increased control (Mattli 2000: 150). In this sense, sovereignty is being reconfigured through voluntary agreements but not necessarily diminished. If autonomy was traded for more economic security in ASEAN, the damage caused by the Asian crisis could have been limited as the 1997 experience clearly showed how interdependent the region is and the vulnerability of individual state policies in containing the spread.

In ASEAN, there are still other challenges that need to be taken into consideration. Apart from differing political systems (from democracy to military regime) and a general lack of trust, the Association's expansionist policies have made sovereignty reconfiguration harder. In comparing the accession of prospective candidates in EU and ASEAN, there is a clear distinction between the two. The newer members of ASEAN (CVLM) acceded without much sovereignty bargains that other EU prospective members had to go through. Unlike the EU, ASEAN's only political criterion for its potential members was for them to agree to accept the ASEAN way and in the case of Myanmar, the acceptance of constructive engagement. What attracted them was not national prosperity in exchange for autonomy (as in the case of EU) but political enhancement and external legitimacy in exchange for none. The ASEAN way became a lucrative guarantor of their newly hard-won sovereign rights. They will reject any changes in the sovereignty configuration. It is therefore critical to enmesh the newer member economies with the old in deepening intra-trade to increase interdependency that would lead to the demand for sovereignty bargains and the natural fallout of strict non-intervention terms. 


\section{Consensus Decision-making}

An important norm in ASEAN, consensus or mufakat is both the organization's strong as well as its weak point. The consensus norm puts each member on an equal footing, allowing the smaller and weaker states to have their voices heard (in the absence of legalistic rules) and its non-binding nature gives members the choice to forego initiatives or policies that run contrary to their national interests. Consensus taken provides an impression of unity among fellow members in the eyes of the international community. Furthermore, it confines public disputes and shelters any member from losing face in an international locale.

On the other hand, consensus reached is normally on the lowest and at times the slowest common denominator. It is unable to produce results on contentious and detrimental matters (the economic meltdown being a case). Since the responsibility for a decision is spread among the group, no one member can be found accountable for the consequences of the decision. It drags the organization from evolving rapidly. No doubt, this will become even more acute with enlargement as it increases ASEAN's political and economic diversity and complicates the decision making process (see International Herald Tribune, 22 April 1999; Asiaweek, 25 December 1998). Some problems occurring from expansion are as follows. First, the CVLM countries' commitment to the Association remains fairly weak. Even after seven years in ASEAN, Myanmar has continued to defy popular pressure with its antics and caused the organization great embarrassment. With their recent membership, it would take more than just a few years to create a sense of belonging. Second, many of them lack the resources and funds to carry out ASEAN's activities and implement agreements reached at the regional level. Developmental assistance from older members would certainly help ease the transition but the economic difficulties endured after 1997 is putting a burden on all parties. Countries like Indonesia are still trying hard to kick start their battered economies. It wouldn't be surprising if the realization of the Vision 2020 is pushed further back. Third, the number of political ideologies or state systems has increased accordingly. Different variants of communism, socialism and military regime are introduced. This has not been an immediate problem because non-intervention continues to be observed. But lately, signs of discontent are manifesting themselves against Myanmar's recent activities and they could well become the centre of contention as the organization intensifies its move towards integration. There will be a need for more homogeneous political governance between the ten member countries. It is in this respect that the 
ASEAN-four would have to evolve at a much faster rate both politically and economically to close ranks with the ASEAN-six countries.

Being aware of the expansion problem and the difficulty in getting consensus, the Association has resorted to adopting the 'Ten minus $\mathrm{X}^{\prime}$ principle. In getting around the consensus problem, this principle allows those who are ready to move forward with liberalization do so without being held back by the slower ones. The most obvious example is the acceptance of a two-tier AFTA. The original six ASEAN members would surge ahead with plans while the CVLM members are given more time to catch up with reform measures. Free from constraints, the ASEANsix can better position themselves to compete directly with the Chinese economy. However, the fear is that it may widen instead of closing the gap and cause more tension between mainland and maritime Southeast Asia. ${ }^{12}$ The new trend of bilateral free trade arrangements led by Singapore could increase wealth disparities and create resentment and envy in those who may not have the means or be in the position to do the same. At present however, the ASEAN-four is moving to close the gap. In 1999, the combined gross national income per capita in terms of purchasing power parity for the older members was 9.17 times more than the newer members while it went down to 7.87 times in 2002 (The World Bank). ${ }^{13}$ This development should be further encouraged by having institutional measures in place to guarantee redistribution of income in the direction of the poorer members to maintain the integration of ASEAN.

Consensus, as traditionally understood, is no longer capable of defending the ideals of the organization in a global environment that is increasingly intrusive and competitive. Internally, it is causing some members to get restless and impatient. With the 'Ten minus $X$ ' formula, consensus has been redefined and as such does not connote unanimity. One is not obliged to wait for another. But while it is not unanimity (the outcome may not reflect everyone's preference), consensus decisionmaking still calls for general agreement and the resolving of objections as part of the process that will, above all, take time. As ASEAN matures, it should display more flexibility in its decision-making process by introducing majority voting for issues that cannot afford the luxury of time. A fair voting process can prevent coercion and manipulation that are at times associated with consensus. The majority vote is also a good method to arrive at decisions on issues and not to defer or put on hold in a way which will subsequently create a large backlog of undecided matters. Clearly, the rapid economic development of China and India is threatening the Association's traditional approach of taking matters 
slowly and step by step. There is hardly any room for mistrust and suspicion. Consensus decision making will have to be further rethought and reconfigured to best support the complexities of institutionalism that is increasingly seen as inevitable in a growing ASEAN.

The call to speed up integration by Singapore and Thailand during last year's Bali Summit is an obvious indication of restlessness within the organization. Their readiness to work with each other should not be bogged down by having to wait for time consuming consensus in deciding on the 'Two minus $X^{\prime}$ ' approach (any two countries can work together first on specific sectors while the others can join in later). Allowing Singapore and Thailand to surge ahead with their plans for cooperation can later place them in a good position to assist in the development of other slower member economies. It could well be an answer to the quest for a benevolent leader or a coalition of leaders which has been noted as an important condition for successful integration. In exchange, there must be commitment to assume some sort of a paymaster role in easing distributional tensions and other foreseeable conflicts within the group. This will entail sovereignty bargains and the shouldering of more responsibilities in the effort to create a well integrated and successful ASEAN.

\section{Conclusion}

In reviewing the analysis of the determinants of the success and failure of regional integration, this study has managed to identify a deeper root cause of the reasons that are obstructing ASEAN from realizing its stated integration goals. The problem generally lies in the Association's diplomatic culture - the working tradition that has come to be understood as the ASEAN way or the ASEAN process. It is a guiding principle that has over the years built confidence and trust among the members in the region. It has generated a certain level of comfort and understanding between the member states.

However, the ASEAN way in its current configuration is not competent to steer the region towards an integrated community. The fact that ASEAN is built on norms and shaky institutional structures will not help it to weather the storm of globalization and new regional challenges posed by two neighbouring giants, China and India. Furthermore, a second Asian crisis must be avoided at all cost. It is in the light of these factors, among others, that the paper calls for the Association to make an urgent priority of strengthening itself internally. The ASEAN diplomacy must be reviewed, reconfigured and supplemented if there are going to 
be genuine efforts at integration. The reconfiguration of the norms of sovereignty, non-intervention and consensus and the supplementation of 'commitment institutions' will strengthen ASEAN's core foundation and speed up the process as the organization no longer has the benefit of time. Elimination of those norms do not pose a viable option and by this recognition, the paper breaks away from traditional literatures and introduces concepts of sovereignty bargaining and majority voting that the Association should explore to help it overcome some of the limitations of its diplomatic culture. Furthermore, it is equally important to recognize that the three norms are interlinked and the reconfiguration of one may affect the other. A move to adopt constructive interference, for example, may require a shift in the consensus decision making process and such adoption may not be possible without some form of sovereignty bargain between the members. Likewise, the introduction of 'commitment institutions' will require the alteration of the stringent principles of non-intervention and sovereignty.

From the review of the conditions for successful integration, the paper finds that the reasons promulgated by Mattli and Webber are insufficient in explaining why ASEAN has not been successful in its integration quest. The measurement for 'successfulness' based on the understanding of western integration models or on pure economic factors or even certain external variables risk over-generalizing and overlooking the internal complexities of an organization such as ASEAN which has been in existence for more than 30 years and would therefore suggest the presence of a political culture that plays a fundamental role in shaping and dictating the interaction of member countries. The ASEAN way is an important criterion that must be factored in to avoid too simplistic explanations that are incapable of fully capturing the intricacies of the region.

The Association's enlargement exercise has proved to be an expensive adventure. It must carefully consider the consequences if there is to be an accession of East Timor. The focus now should be fully geared towards the internal strengthening of the organization and the further involvement of a wider circle of non-elites and the general population in the effort to build a competitive institution, one that can be identified and be proud of by the people of ASEAN.

Benny Teh Cheng Guan is a Ph.D. Candidate at The Graduate School of SocioEnvironmental Studies, Kanazawa University. 


\section{NOTES}

* Acknowledgements. This article is a revised version of a paper presented to the $6^{\text {th }}$ ASEAN Inter-University Seminars on Social Development at Science University of Malaysia, 14-16 May 2004. The author would like to thank the editors and an anonymous reviewer of The Copenhagen Journal of Asian Studies for their helpful comments and suggestions. Special thanks to Ai Higuchi, Jennifer Hazzelby, Shaun Narine and Masahiro Kashima for their assistance and comments on an earlier draft of this article.

1 The framework is derived from Walter Mattli (1999) and Douglas Webber (2001).

2 For more details, see Busse (1999) and Snitwongse (1995: 520).

3 Acharya (2001: 47-68) discerns between ASEAN norms like non-interference, peaceful resolution, non-use of force, and regional autonomy and the ASEAN way such as informality, consensus-building and consultation.

4 During the $23^{\text {rd }}$ ASEAN Economic Ministers Meeting in Kuala Lumpur in 1991, five proposals were put on the table. There were the Malaysian EAEG, the Thai AFTA, the Indonesian CEPT, the Philippine ASEAN Treaty of Economic Cooperation and the Singaporean sub-regional growth triangles. Dr Mahathir Mohamad pushed strongly for the EAEG, casting doubt on the 'ability of ASEAN to create an operational free trade area'. The final consensus led to the birth of AFTA and CEPT, achieved during the Singapore ASEAN Summit in January 1992 (Palmujoki 2001: 54-55).

5 This is based on Steven David's theory of omnibalancing, which argues that the main actors of Third World countries in international politics are individual rulers and not the state (David 1991).

6 As Funston (2000: 4) pointed out that the practice of non-intervention has caused 'plans for economic cooperation [to gather] dust as countries adhered to protectionist policies and refused to make concessions to neighbours'.

7 Under Thailands's new Premier, Chatichai Choonhavan, a series of initiatives were taken towards the Indochina states. First, a change in economic policy gradually increased export items to Laos and the normalization process let to Chatichai's visit in 1988. Second, Chatichai departed from the established Thai policy to recognize the Phnom Penh government by welcoming Prime Minister Hun Sen to an informal meeting in 1989. Third, Thai Foreign Minister Siddhi Savetsila formally visited Vietnam in 1989 under Chatichai's persuasion. The visit not only signalled support from the Thai Foreign Ministry for the prime minister's diplomacy but also brought home successful trade negotiations and the acknowledgement for neutralization of Cambodia (Sudô 1996: 64-68).

8 Indonesia, at best, was accepted as 'first among equals' (Lee 2000: 370).

9 It is also worth noting here that ASEAN cannot be formed on the grounds of anti-communism for history has shown that Indonesia rejected the Association of Southeast Asia (ASA) because of its perceived political connections to the Southeast Asian Treaty Organization (SEATO).

10 For an interesting account on the accession of Myanmar into ASEAN, see Palmujoki (2001: 47-49).

11 Yamakage notes that the norm of non-interference as a barrier can be removed in long term when democracy matures in each member state.

12 For some viewpoints on this issue, see Asia Times Online 20 February 2003.

13 Statistical data was unavailable for Brunei and Myanmar. 


\section{REFERENCES}

Acharya, Amitav 1995. 'A Regional Security Community in Southeast Asia?' Journal of Strategic Studies 18(3): 175-200.

-2001. Constructing a Security Community in Southeast Asia: ASEAN and the Problem of Regional Order. New York: Routledge.

Asia Times Online, 20 February 2003.

Asiaweek, 25 December 1998.

Busse, Nikolas 1999. 'Constructivism and Southeast Asian Security'. The Pacific Review 12(1): 39-60.

Chatterjee, Srikanta 1990. 'ASEAN Economic Co-operation in the 1980s and 1990s'. In Alison Broinowski (ed.). ASEAN into the 1990s. London: Macmillan: 58-82.

David, Steven 1991. 'Explaining Third World Alignment.' World Politics 43(2): 233-56.

Funston, John 2000. ASEAN and the Principle of Non-Intervention - Practice and Prospects. Singapore: Institute of Southeast Asian Studies.

Haacke, Jurgen 1999. 'The Concept of Flexible Engagement and the Practice of Enhanced Interaction: Intramural Challenges to the 'ASEAN way'.' The Pacific Review 12(4): 581-611.

-2003. 'ASEAN's Diplomatic and Security Culture: A Constructivist Assessment'. International Relations of the Asia-Pacific 3 (1): 57-87.

International Herald Tribune, 22 April 1999.

Kuroyanagi, Yoneji 2003. ASEAN 35nen no Kiseki: 'ASEAN way' no Kouyou to Genkai [35 years of ASEAN Miracle: The Applicability and Limits of the ASEAN way]. Tokyo: Yuushindou Koubunsha.

Lee, Kuan Yew 2000. From Third World to First. The Singapore Story: 1965-2000. Singapore: Singapore Press Holdings.

Leifer, Michael 1989. ASEAN and the Security of Southeast Asia. London: Routledge.

Litfin, Karen 1997. 'Sovereignty in World Ecopolitics.' Mershon International Studies Review 41: 167-204.

Mattli, Walter 1999. The Logic of Regional Integration. Cambridge: Cambridge University Press.

-2000. 'Sovereignty Bargains in Regional Integration.' International Studies Review 2(2): 149-180.

Narine, Shaun 1997. 'ASEAN and the ARF: The Limits of the 'ASEAN way'.' Asian Survey 37(10): 961-978.

-2002. Explaining ASEAN: Regionalism in Southeast Asia. Boulder: Lynne Rienner Publishers.

Nischalke, Tobias Ingo 2000. 'Insights from ASEAN's Foreign Policy Co-operation: The 'ASEAN way', a Real Spirit or a Phantom?' Contemporary Southeast Asia 22(1): 89-112.

Noor, Farish 1999. 'Values in the Dynamics of Malaysia's Internal and External Political Relations'. In Han Sung-Joo (ed.). Changing Values in Asia: Their Impact on Governance and Development. Tokyo: Japan Center for International Exchange: 146-76.

Palmujoki, Eero 2001. Regionalism and Globalism in Southeast Asia. New York: Palgrave.

Pitsuwan, Surin 2001. Future Directions for ASEAN. Singapore: Institute of Southeast Asian Studies.

Snitwongse, Kusuma 1995. 'ASEAN's Security Cooperation: Searching for a Regional Order.' The Pacific Review 8(3): 518-530.

Sudô, Sueo 1996. Tounan Ajia Kokusai Kankei no Kouzu: Riron Chiikigaku wo Mezashite [Composition of Southeast Asian International Relations: Towards a Theoretical Area Study]. Japan: Keisou Shobou. 
Takeuchi, Junko 1999. 'Foreign Direct Investment and Economic Cooperation'. In Sueo Sekiguchi and Makito Noda (eds). Road to ASEAN-10: Japanese Perspectives on Economic Integration. Tokyo: Japan Center for International Exchange: 98-132.

The World Bank.

Webber, Douglas 2001. 'Two Funerals and a Wedding?: The Ups and Downs of Regionalism in East Asia and Asia-Pacific after the Asian Crisis.' The Pacific Review 14(3): 339-72.

WTO Trade Statistics 2003.

Yamakage, Susumu 1997. 'Shoki ASEAN Saikou: Reisen Kouzou Shita no Ajia Chiikishuugi to ASEAN' [A Reevaluation of Early ASEAN: Asian Regionalism under the Cold War Structure and the Formation of ASEAN]. Nihon Kokusai Seiji Gakkai [The Japan Association of International Relations] 116: 17-31.

-2001. 'ASEAN no Kihon Rinen no Douyou: Naisei Fukanshou Gensoku wo Meguru Tairitsu to Kyouryoku' [The Convulsion of ASEAN's Fundamental Principle: Conflict and Cooperation concerning the Principle of Non-interference in Domestic Affairs]. In Susumu Yamakage (ed.). Tenkanki no ASEAN: Arata na Kadai he no Chousen [The Turning Point of ASEAN: Challenges to New Problems]. Tokyo: Nihon Kokusai Mondai Kenkyuujyo [The Japan Institute of International Affairs]: 115-42. 